\title{
The role of ductal obstruction on the course of hemorrhagic pancreatitis in the pig
}

\author{
L. Romero Farias, Charles F. Frey, Samuel French and Robert Gunther \\ Department of Surgery, University of California, Davis Medical Center, Sacramento, CA, U.S.A.
}

(Received 12 November 1985; Accepted 22 January 1986)

Key words: Hemorrhagic pancreatitis; ductal obstruction; hyperamylasemia

\section{Summary}

The effect of relieving pancreatitic duct obstruction after the onset of hemorrhagic pancreatitis was investigated. Hemorrhagic pancreatitis was produced in 20 pigs by a bile salt-trypsin retrograde injection technique. In half the pigs the pancreatic duct was permanently ligated, and in the other half the ductal obstruction was relieved 2 $\mathrm{h}$ after the onset of hemorrhagic pancreatitis. The overall mortality rate was the same in both groups by $24 \mathrm{~h}$. No difference was found between the groups in the gross and microscopic appearance of histological samples taken from the pancreas immediately after death. The biochemical parameters measured to assess the severity of pancreatitis such as calcium, BUN, creatinine, glucose, proteins, and hematocrit did not show any difference between the two groups. The serum amylase level, a measure of ductal obstruction, was less at $24 \mathrm{~h}$ and even lower at $48 \mathrm{~h}$ in the release group as compared to the non-release group. This difference suggests that the ductal obstruction was relieved, as the amylase levels declined at 24 and $48 \mathrm{~h}$. Hemodynamic variables, including cardiac output, pulmonary artery pressure, pulmonary wedge pressure, central venous pressure, and aortic pressure were followed. No significant difference was found in any of these parameters between the two groups.

The absence of any significant differences in hemodynamic status, histopathological findings, and biochemical analysis in our pigs, if translatable to man, does not lend support to early operative intervention in gallstone pancreatitis in the hope that those patients who already have hemorrhagic pancreatitis will benefit from early pancreatic ductal decompression.

Correspondence to: Charles F. Frey, M.D., 4301 X Street, Sacramento, CA 95817, U.S.A. 


\section{Introduction}

In 1978, Acosta reported that the mortality of patients with gallstone pancreatitis could be reduced by early (within 24-36 h of symptom onset) operative removal of common-duct stones impacted at the ampulla of Vater [1]. Stone et al. also reported similar results with the use of operative sphincterotomy [2]. They report an outpouring of bile and pancreatic juice after the relief of obstruction.

Acosta et al. attributed the reduced mortality of gallstone pancreatitis following early operative intervention to the prevention of hemorrhagic necrosis of the pancreas resulting from prompt relief of ampullary obstruction [1]. However, the incidence of hemorrhagic necrosis in the historical controls was the same as in the early operative intervention group; $10.4 \%$ (control group) and 10.8\% (early intervention group). Therefore, early operative intervention did not reduce the incidence of hemorrhagic necrosis compared to delayed operative intervention. On the other hand, if there really is an advantage to early operative decompression, it might be attributable, not to the prevention of hemorrhagic necrotizing pancreatitis, as Acosta believes, but to a modification of its course. While ductal obstruction is recognized as an important factor clinically and experimentally in the initiation of pancreatitis since the work of Opie [3] and Archibald [4], the effect of relieving ductal obstruction on the severity of pancreatitis after pancreatitis has been induced has not been fully studied. Ligation of the pancreatic ducts in dogs with pancreatic edema did not show any increase in adverse effects on previous inflammatory alteration in the pancreas [5]. However, the effect of relieving ductal obstruction after the initiation of hemorrhagic pancreatitis has not been investigated. It has been assumed by many investigators that once the pancreas has undergone hemorrhagic necrotizing change, as described by Fitz in 1889 [6], and experimentally by Rich and Duff in 1936 [7], the changes in the pancreas were irreversible. Whether relieving the ductal obstruction would have an effect on the local lesion in the pancreas or on the systemic effects of pancreatitis has not been investigated.

The purpose of our experiment was to determine if the severity, as judged by the pancreatic lesion or systemic effects of hemorrhagic pancreatitis induced in pigs, could be modified by relieving the ductal obstruction. We produced hemorrhagic pancreatitis in pigs by a bile salt-trypsin retrograde injection technique [8]. This technique produces a hemorrhagic necrotizing pancreatitis, In half the pigs, the pancreatic duct was permanently ligated, and in the other half the obstruction of the duct was relieved $2 \mathrm{~h}$ after the induction of hemorrhagic pancreatitis.

\section{Materials and Methods}

Twenty young, healthy, female pigs weighing $15-20 \mathrm{~kg}$ were fasted $12 \mathrm{~h}$ prior to surgery. One hour pre-operatively they were treated with gentamycin $(1.2 \mathrm{ml} / \mathrm{kg})$ and 
clindamycin (150 mg) given intravenously (i.v.). Anesthesia was carried out with a combination of droperidol $20 \mathrm{mg} / \mathrm{ml}$ and fentanyl $4 \mathrm{mg} / \mathrm{ml}$ (Inovar $1 \mathrm{ml} / 15 \mathrm{~kg}$ ) followed by endotracheal intubation. Anesthesia was maintained with $1-2 \%$ doses of Halothane carried in a $50 / 50 \%$ nitrous oxide/oxygen mixture. Ventilation was controlled by a Bennet Volume ventilator throughout the surgical procedure. A SwanGanz catheter was placed in the pulmonary artery via the jugular vein to obtain cardiac output $(\mathrm{CO})$ by thermodilution, and a silastic catheter was placed in the thoracic aorta through the carotid artery to measure arterial pressure (AO). Pulmonary arterial pressure (PA), pulmonary artery occluded pressure (PAW), and central venous pressure (CVP) were measured with Gould p23 Db pressure transducers and recorded on a 5-channel strip chart recorder at regular intervals. Cardiac output was measured using an Edwards cardiac output computer. Baseline blood samples for BUN, creatinine, amylase, calcium, glucose, total protein, and hematocrit determinations were obtained before surgery and postoperatively at 4, 8, 24 and $48 \mathrm{~h}$. The pigs were placed in a supine position on a heating blanket and laparotomy was carried out through a midline incision. The pancreatic duct was isolated and cannulated and hemorrhagic pancreatitis was produced by a fresh, sterile solution of $15 \%$ sodium taurocholate (Sigma Chemical Company, St. Louis, MO) and 10000 benzoyl L-arginine ethyl ester hydrochloride (BAEE) units of crystallized trypsin (Tryptar) per $\mathrm{ml}$ titrated to a $\mathrm{pH}$ of 8 . Pressure during the injection period was maintained under $50 \mathrm{~cm} / \mathrm{H}_{2} \mathrm{O}$. The laparotomy was not closed until $2 \mathrm{~h}$ after pancreatitis had been induced in the group of animals with permanent obstruction after ligating the main pancreatic duct. The laparotomy was closed at an equivalent time in the other group, $2 \mathrm{~h}$ after the main pancreatic duct had been initially obstructed and then released from obstruction. To ensure the pancreatic duct's patency after the $2 \mathrm{~h}$ of obstruction, the pancreatic duct was cannulated through the duodenum with a 20 -gauge silastic cannula and the cannula maintained in its intraluminal position by a ligature around the duct external to the duodenum containing the cannula. Flow of juice through the cannula was considered evidence of patency. Anesthesia was maintained for an equivalent time in both groups.

To determine an adequate injection volume, a series of experiments using doses of 1 and $2 \mathrm{ml} / \mathrm{kg}$ of bile salt-trypsin mixture was performed. The pigs were then divided into the following groups:

Group $A$. Eight animals were given $2 \mathrm{ml} / \mathrm{kg}$ of bile salt-trypsin mixture and divided into two groups. Four animals were permanently obstructed and 4 were transiently obstructed for $2 \mathrm{~h}$.

Group $B$. Comprised 6 animals who had a retrograde injection of $1 \mathrm{ml} / \mathrm{kg}$ followed by obstruction of the pancreatic duct, which was removed after $2 \mathrm{~h}$.

Group C. Comprised 6 animals with a retrograde injection of $1 \mathrm{ml} / \mathrm{kg}$ followed by permanent obstruction of the pancreatic duct which was maintained until death.

One liter of Ringer's lactate solution was given i.v. during laparotomy and another 11 was administered at a rate of $200 \mathrm{cc} / \mathrm{h}$ over the following $8 \mathrm{~h}$. Animals were 
allowed to recover from anesthesia and were kept in cages for tracing hemodynamic and biochemical parameters.

The animals were autopsied as soon as they expired or were sacrificed by infusion of an overdose of pentobarbital $48 \mathrm{~h}$ after the surgical procedure. At autopsy, under sterile conditions, the hemorrhagic ascitic fluid (HAF) was measured and saved, and organ samples from the pancreas, kidney, and liver were fixed in formalin for histological comparison between the groups.

\section{Results}

Of the 20 animals studied, the first 8 were given $2 \mathrm{ml}$ of bile salt-trypsin solution which produced $100 \%$ mortality in the first $12 \mathrm{~h}$, whether or not the obstruction was released. Because of this high mortality, the amount of the injection was reduced, to determine if the benefit of ductal decompression might be evident if a less severe pancreatic injury were produced. The remaining 12 pigs received $1 \mathrm{ml} / \mathrm{kg}$ body wt. In the first $12 \mathrm{~h}$, one death occurred in the released group (17\% mortality) and no deaths occurred in the obstructed group. By $24 \mathrm{~h}$, both groups had a mortality rate of $50 \%$ (Table I).

Except for the aortic pressure, the hemodynamic parameters measured showed a decrease (Table II). At $8 \mathrm{~h}$, CO decreased $44 \%$ and $46 \%$, and CVP decreased 38 and $32 \%$, for the groups released and obstructed, respectively. At 24 h, CVP increased $50 \%$ in comparison to the 8 -h levels, but no difference was seen between the groups. By $48 \mathrm{~h}, \mathrm{CO}, \mathrm{CVP}$, and PAW returned to baseline levels. However, there was no significant difference between the hemodynamic variables in any interval when the two groups were compared.

Table III lists several biochemical parameters measured to determine the severity of pancreatitis or the degree of ductal obstruction of the pancreas. When the released group was compared to the obstructed group, no significant difference was found between any of the biochemical parameters measured (Table III). Serum amylase, a measure of ductal obstruction after induction of hemorrhagic pancreatitis, showed no appreciable difference in releaesed and non-released pigs at 4 and $8 \mathrm{~h}$ (Fig. 1). The

TABLE I

SURVIVAL RATE

\begin{tabular}{lcccc}
\hline Group & Baseline & $12 \mathrm{~h}$ & $12-24 \mathrm{~h}$ & $48 \mathrm{~h}$ \\
\hline Released & $100 \%$ & $83 \%$ & $50 \%$ & $50 \%$ \\
$(n)$ & 6 & 5 & 3 & 3 \\
Obstructed & $100 \%$ & $100 \%$ & $50 \%$ & $50 \%$ \\
$(n)$ & 6 & 6 & 3 & 3 \\
\hline
\end{tabular}


TABLE II

HEMODYNAMIC CHANGES

\begin{tabular}{|c|c|c|c|c|c|c|c|c|c|c|}
\hline & Baseline & & $4 \mathrm{~h}$ & & $8 \mathrm{~h}$ & & $24 \mathrm{~h}$ & & $48 \mathrm{~h}$ & \\
\hline & Rel. ${ }^{a}$ & Obst. & Rel. & Obst. & Rel. & Obst. & Rel. & Obst. & Rel. & Obst. \\
\hline \multirow[t]{2}{*}{$\mathrm{AO}^{\mathrm{b}}$} & 63 & 79 & 75 & 88 & 71 & 76 & 78 & 103 & 88 & 100 \\
\hline & \pm 15.6 & \pm 16 & \pm 33 & \pm 17 & \pm 16 & \pm 16 & \pm 30 & \pm 15 & \pm 16 & \pm 8.0 \\
\hline \multirow[t]{2}{*}{ PA } & 18 & 20 & 16.6 & 16 & 16 & 18 & 14 & 16 & 14 & 17 \\
\hline & \pm 4.9 & \pm 4.5 & \pm 2.7 & \pm 2.6 & \pm 2.7 & \pm 4.4 & \pm 2.0 & \pm 2.0 & \pm 2.0 & \pm 1.2 \\
\hline \multirow[t]{2}{*}{ PAW } & 4.9 & 5.5 & 2.6 & 2.8 & 3.0 & 3.7 & 2.0 & 3.3 & 5.0 & 4.3 \\
\hline & \pm 3.7 & \pm 2.8 & \pm 2.1 & \pm 2.4 & \pm 2.5 & \pm 3.7 & \pm 2.8 & \pm 1.1 & \pm 2.8 & \pm 2.5 \\
\hline \multirow[t]{2}{*}{ CVP } & 1.7 & 1.5 & 0.1 & 0.8 & 0 & 0.3 & 0.8 & 1 & 1 & 2 \\
\hline & \pm 1.0 & \pm 0.8 & \pm 0.4 & \pm 0.9 & \pm 0 & \pm 2.4 & \pm 0.5 & \pm 1 & \pm 1.7 & \pm 2 \\
\hline \multirow[t]{2}{*}{$\mathrm{CO}$} & 3.8 & 4.1 & 2.1 & 2.2 & 2.1 & 2.2 & 2.7 & 2.2 & 3.3 & 3.0 \\
\hline & \pm 0.8 & \pm 1.0 & \pm 0.2 & \pm 0.6 & \pm 0.9 & \pm 0.2 & \pm 0.4 & \pm 0.5 & \pm 0.6 & \pm 0.1 \\
\hline
\end{tabular}

a Rel., released group; Obst., obstructed group.

b AO, mean aortic pressure; PA, pulmonary arterial pressure; PAW, pulmonary arterial occluded pressure; CVP, central venous pressure; $\mathrm{CO}$, cardiac output.

TABLE III

\section{BIOCHEMICAL PARAMETERS}

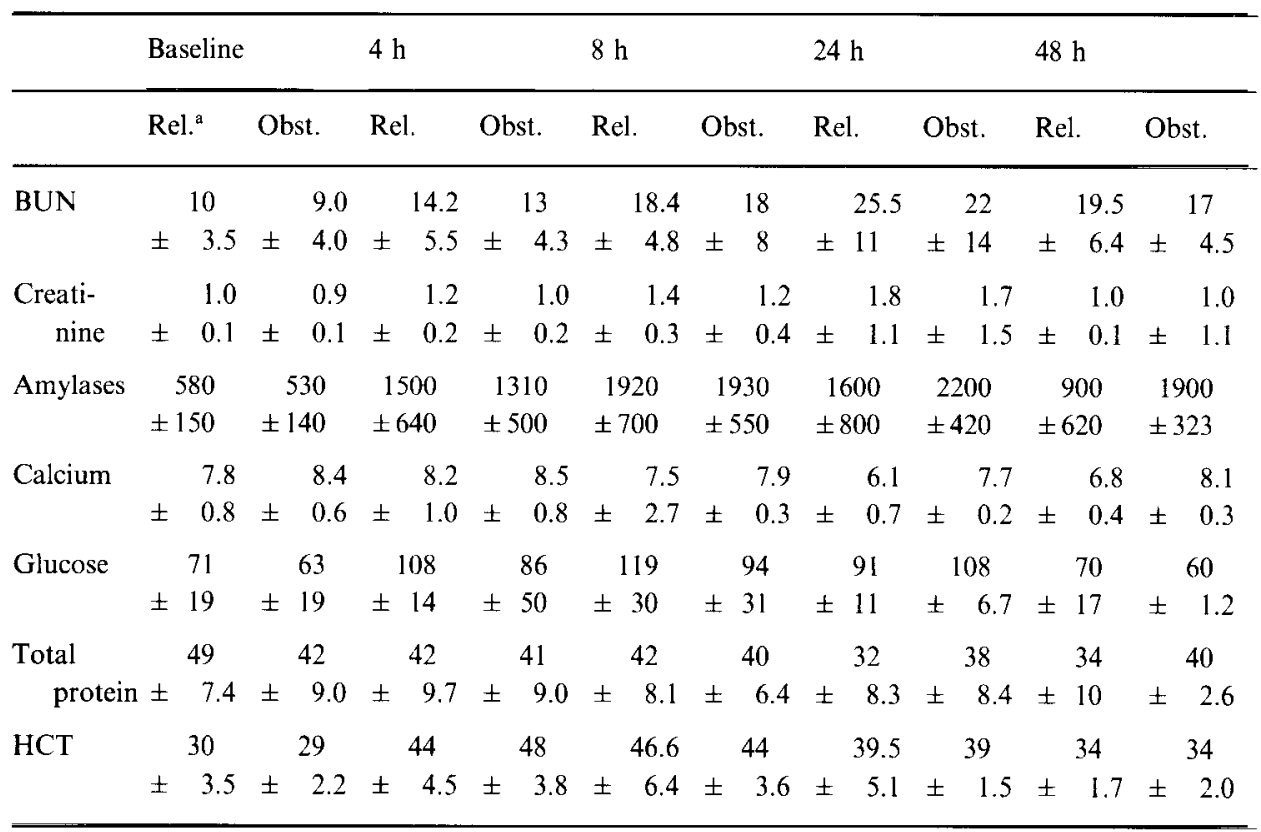

Rel., released group; Obst., obstructed group. 


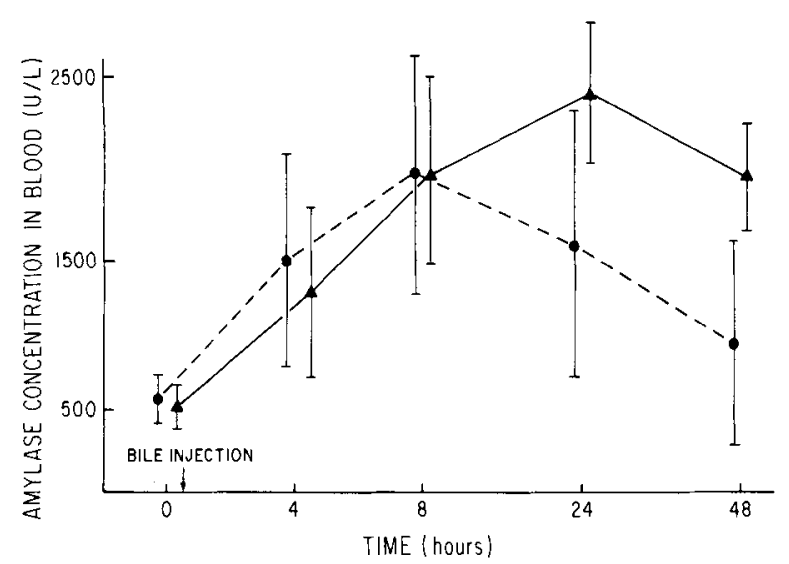

Fig. 1. Changes in serum amylase levels in both groups are shown. No appreciable difference was found between the two groups at 4 and $8 \mathrm{~h}$. By $48 \mathrm{~h}$ there was a major lowering of the serum amylase in the release group compared to the non-release group, following the trend established at $24 \mathrm{~h}$. There was no overlap between the two groups at $48 \mathrm{~h}$.

average level of serum amylase at $24 \mathrm{~h}$ was less in the release group than in the non-release group, but the difference was not statistically significant. By $48 \mathrm{~h}$, there was a major lowering of the serum amylase in the release group as compared to the non-release group, following the trend established at $24 \mathrm{~h}$. While this difference is not statistically significant because of the small numbers involved, there was no overlap between the two groups at $48 \mathrm{~h}$.

After injection, edema and hemorrhage appeared in the pancreas, while at autopsy the gland was extensively necrotic. The histopathological findings showed an extensive necrotizing pancreatitis, interstitial edema and hemorrhage in all pigs. Fat necrosis surrounding the pancreatic tissue was also present in all animals, while bacterial growth was present in only 3 pigs. Liver histology showed a hypoxic damaged tissue in almost all cases, with central necrosis of the liver being present in only one animal. The kidney did not appear damaged in the great majority of the cases. One animal presented signs of disseminated intravascular coagulation with fibrin accumulation in the glomeruli. Acute tubular necrosis was observed in other cases.

An average of $1.425 \pm 594 \mathrm{ml}$ of hemorrhagic ascitic fluid (HAF) was recovered from the released group and $1.332 \pm 587 \mathrm{ml}$ (HAF) from the obstructed group.

\section{Discussion}

The timing of surgical intervention on patients with gallstone pancreatitis is controversial $[1,2,9]$. That surgery should be performed during the patient's first admission is well established, based on the likelihood of a recurrent attack with $69 \mathrm{mth}$ post-operation [9-15]. However, there is a lack of agreement about whether the 
patient should be operated upon as an emergency as soon as possible after hospital admission $[1,2,9,10,16,17]$.

Ranson believes the operation on the biliary tract should be delayed [9]. Acosta et al. believe the operation in patients with gallstone pancreatitis should be performed within 24-36 h of the onset of symptoms [1]. To support their assertion, they point to the lower mortality rate: $2 \%$ for 46 patients operated on early, compared to the historical control of $16 \%$ for 86 patients operated on after $36 \mathrm{~h}$. They attributed the difference in mortality associated with early operation to a reduction in the incidence of hemorrhagic pancreatitis. However, their own data comparing the incidence of hemorrhagic pancreatitis between the early operation group and the historical controls showed no such difference, the incidence being $10 \%$ in each group.

To explain the reduced mortality between the early and late operating groups reported by Acosta et al., we examined another possibility that early relief of obstruction might modify the severity of hemorrhagic pancreatitis. In order to simulate the patients described by Acosta et al., many of whom died from hemorrhagic necrotizing pancreatitis, it was necessary to produce a severe pancreatitis. When we did this, we found no difference in mortality between pigs in whom the pancreatic ductal obstruction was released $2 \mathrm{~h}$ after the onset of hemorrhagic pancreatitis, and those in whom the duct remained obstructed.

The cardiovascular monitoring, which was continued in all animals until death or killing, never, on any occasion, showed a difference between the obstructed or unobstructed duct groups. The cardiac output, central venous pressure, aortic pressure, pulmonary artery pressure, and pulmonary wedge pressure did not improve after release of the duct obstruction at $2 \mathrm{~h}$. It might be argued that more vigorous fluid replacement may have elicited some difference between the released and obstructed group. The $15-20-\mathrm{kg}$ pigs received 21 of fluid over $8 \mathrm{~h}$, equivalent to $8-101 \mathrm{in}$ a $70-\mathrm{kg}$ adult human. The decrease in cardiac output and pulmonary wedge pressure indicates that the pigs may have received even more fluid. However, organ perfusion was well maintained. The lack of evidence of marked hemoconcentration or renal failure belie the presence of major fluid deficits in the pigs with pancreatitis. Additionally, equal amounts of ascitic fluid were recorded in the abdominal cavity of the two groups, and no difference was found in the gross appearance of the pancreas, peripancreatic tissue, and surrounding areas. Examination of histological specimens of the pancreas, liver, and kidney for further evidence of microscopic difference in the degree of tissue damage failed to reveal any significant difference between the two groups. The slight differences in the extent of the lesions in the pancreatic tissue did not correlate with whether or not the pancreatic duct obstruction was released.

These findings indicate that in our model of pancreatitis with complete ductal blockage, tissue injury occurs rapidly and, within $2 \mathrm{~h}$, most of the damage and resulting pathological changes have been initiated. At the same time, the serum amylase levels suggest that the ductal obstruction was relieved, as the amylase levels declined at 24 and $48 \mathrm{~h}$. Biochemical parameters assessing the severity of the pancreatitis 
failed to show any differences. The serum amylase level is not a measure of the severity of pancreatitis $[18,19]$. The serum amylase levels reflect three variables: acinar production of amylase, the degree of ductal obstruction and renal clearance of amylase $[20,21]$. Among these three variables, only the degree of ductal obstruction was altered during our experiment. While serum amylase levels in the dog reflect amylase from sources in addition to the pancreas, there is no reason to suppose the difference found between the two groups, released and non-released, could result from nonpancreatic sources of amylase.

The absence of any significant differences in hemodynamic status, pathological findings and biochemical analysis after ductal decompression does not lend support to early operative intervention in gallstone pancreatitis in the hope that the patients who already have hemorrhagic pancreatitis will benefit from pancreatic ductal decompression. Once the pancreas has undergone hemorrhagic change the process seems irreversible in the pig and not appreciably altered by ductal decompression. That ductal decompression did occur in our pigs is suggested by the lowering of serum amylase at $24 \mathrm{~h}$ which is increasingly evident at $48 \mathrm{~h}$ in the released pigs as compared to those pigs in whom the ligature was permanent. Serum amylase levels reflect the degree of ductal obstruction of the pancreas, not the severity of injury.

It seems likely the difference in mortality in patients with gallstone pancreatitis (noted by Acosta et al. [1]) between patients having early or late operations was attributable to his use of historical controls for his late operation group. The lower mortality in the early operation group may have resulted not from early operative decompression of the pancreatic duct in patients with hemorrhagic pancreatitis, but from improvement in surgical intensive care unit management of patients with severe and hemorrhagic pancreatitis in his more recently studied patients.

\section{References}

1 Acosta, J.M., Rossi, R., Galli, O.M.R., Pellegrini, C.A. and Skinner, D.B. Early surgery for acute gallstone pancreatitis: evaluation of a systemic approach, Surgery, 1978; 83: 367-370.

2 Stone, H.H., Fabian, T.C. and Dunlop, W.E. Gallstone pancreatitis biliary tract pathology in relation to time of operation, Ann. Surg., 1981; 194: 305-312.

3 Opie, E.L. The etiology of acute hemorrhagic pancreatitis, Bull. Johns Hopkins Hospital, 1901; 12 : 182-188.

4 Archibald, E. The experimental production of pancreatitis in animals as the result of the resistance of the common duct sphincter, Surg. Gynecol. Obstet., 1919; 28: 529-545.

5 Engel, S., Remine, W.H., Dockerty, M.B., Grindlay, J.H. and Bartholomew, L.G. Effect of ligation of pancreatic ducts on chronic pancreatitis, Arch. Surg, 1962; 85: 1031-1035.

6 Fitz, R.H. Acute pancreatitis, a consideration of pancreatic hemorrhage, hemorrhagic suppurative, and gangrenous pancreatitis and of disseminated fat necrosis, Boston Med. Surg. J., 1889; 120: 187187, 205-207, 229-235.

7 Rich, A.R. and Duff, G.L. Experimental and pathological studies on the pathogenesis of acute haemorrhagic pancreatitis, Bull. Johns Hopkins Hospital, 1936; 58: 212-259.

8 Thorpe, C.D. and Frey, C.F. Experimental pancreatitis in pigs, Arch. Surg., 1971; 103: 720-723. 
9 Ranson, J.H.C. The timing of biliary surgery in acute pancreatitis, Ann. Surg., 1979; 189: 654-663.

10 Dixon, J.A. and Hillam, J.D. Surgical treatment of biliary tract disease associated with acute pancreatitis, Am. J. Surg., 1970; 120: 371-375.

11 Elfstrom, J. The timing of cholecystectomy in patients with gallstone pancreatitis, Acta Chir. Scand., 1978; 144: 487-490.

12 Frey, C.F. The operative treatment of pancreatitis, Arch. Surg., 1969; 98: 406-417.

13 Glenn, F.G. and Frey, C.F. Reevaluation of the treatment of pancreatitis associated with biliary tract disease, Ann. Surg., 1964; 160: 723-736.

$14 \mathrm{Kim}, \mathrm{V}$. and Sheth, W. Optimal timing of surgical intervention in patients with acute pancreatitis associated with cholelithiasis, Surg. Gynecol. Obstet., 1980; 150: 449-501.

15 Paloyan, D., Simonowitz, D. and Skinner, D.B. The timing of biliary tract operations in patients with pancreatitis associated with gall-stones, Surg. Gynecol. Obstet., 1975; 141: 737-739.

16 Kelly, T.R. Gallstone pancreatitis: the timing of surgery, Surgery, 1980; 88: 345-350.

17 Safrany, L. and Cotton, P.B. Urgent duodenoscopic sphincterotomy for acute gallstone pancreatitis, Surgery, 1981; 89: 424-428

18 Hermann, R.E. and Davis, J.H. The role of incomplete pancreatic duct obstruction in the etiology of pancreatitis, Surgery, 1960; 48: 318-329.

19 Menguy, B.R., Hallenbeck, A.G., Bollman, L.J. and Grindlay, H.J. Ductal and vascular factors in etiology of experimentally induced pancreatitis, AMA Arch. Surg., 1957; 74: 881-889.

20 Gullick, H.D. Relation of the magnitude of blood enzyme elevation to severity of exocrine pancreatic disease, Am. J. Dig. Dis., 1973; 18: 375-383.

21 Salt II, B.W. and Schemker, S. Amylase, its clinical significance: a review of the literature, Medicine, 1976; 55: 269-289. 